bioRxiv preprint doi: https://doi.org/10.1101/2021.12.01.470808; this version posted December 1, 2021. The copyright holder for this preprint

(which was not certified by peer review) is the author/funder. All rights reserved. No reuse allowed without permission.

\title{
ESR2 regulates indian hedgehog signaling in neonatal rat ovary
}

\author{
Iman Dilower ${ }^{1,2 \#}$, V. Praveen Chakravarthi ${ }^{1,2,3 \# *}$, Eun B. Lee ${ }^{1,2}$, Subhra Ghosh ${ }^{1,2}$, Shaon Borosha ${ }^{1}$, Richita Roy ${ }^{1}$, \\ Saeed Masumi ${ }^{1}$, Anohita Paul ${ }^{1}$, Hindole Ghosh ${ }^{1}$, Michael W. Wolfe ${ }^{2,3}$, M. A. Karim Rumi ${ }^{1,3 *}$ \\ ${ }^{\#}$ Equal contributing authors; *Corresponding author
}

${ }^{1}$ Pathology and Laboratory Medicine, ${ }^{2}$ Molecular and Integrative Physiology, ${ }^{3}$ Reproduction and Perinatal Research,
University of Kansas Medical Center, Kansas City, KS 66160

The transcriptional regulatory function of estrogen receptor $\beta$ (ESR2) is essential for the regulation of primordial follicle activation (PFA). Increased PFA due to the loss of ESR2 becomes evident as early as postnatal day 8 (PND8). To identify the ESR2-regulated genes that control PFA, we performed RNA-seq analyses of wildtype, and Esr2 knockout $\left(E s r 2^{K O}\right)$ neonatal rat ovaries collected on PND4, PND6, and PND8. Among the differentially expressed genes in $E s r 2^{K O}$ ovaries, indian hedgehog (Ihh) displayed the highest downregulation among the ovary enriched genes. IHH regulated genes including Hhip as well as the steroidogenic enzymes were also downregulated in $E s r 2^{K O}$ rat ovaries. Remarkably, the expression of $I h h$ in $E s r 2^{K O}$ ovaries was not upregulated despite the high levels of $G d f 9$ and $B m p 15$, which are known regulators of Ihh expression in granulosa cells. Our findings suggest that indian hedgehog signaling in the neonatal rat ovary is dependent on ESR2.

Keywords: Ovary, Esr2, RNA-seq, Ihh and Hhip

Correspondence: praghavulu@kumc.edu; mrumi@kumc.edu

\section{Introduction}

Estrogen receptor $\beta$ (ESR2) is the predominant estrogen receptor in mammalian ovary and is essential for follicle development and ovulation (1-3). ESR2 also plays a gatekeeping role to control the rate of primordial follicle activation (PFA) (4). Loss of ESR2 increases PFA leading to premature ovarian insufficiency in Esr2 knockout $\left(E s r 2^{K O}\right)$ rats $(4,5)$. Regulation of PFA is a complex mechanism that involves a number of negative regulators within the PI3-kinase and mTOR pathways (6-8). Several transcriptional regulators like FOXO3A also act like ESR2 to inhibit induction of PFA (9). Although the loss of ESR2 augments the activation of AKT, ERK, and mTOR pathways in $E s r 2^{K O}$ ovaries, the exact molecular mechanism of ESR2-mediated regulation of PFA remains unclear (4).

During ovarian follicle development, activated granulosa cells (GCs) express hedgehog proteins, which are essential for the development, growth, and differentiation of theca cells (TCs) (10-16). The loss of either hedgehog signaling, or its aberrant activation leads to defective differentiation of TCs and failure of ovulation $(12,15)$. The indian hedgehog $(I h h)$, and the desert hedgehog $(D h h)$ genes are expressed in
GCs, whereas the hedgehog receptor Ptchl/Ptch2, the signal transducer $S m o$, as well as the hedgehog target genes like Gli1/Gli2/Gli3 transcription factors are expressed in TCs $(17,18)$. It is also important to note that ESR2 is predominantly expressed in the GCs, while ESR1 is expressed in TCs $(19,20)$. However, it remains unknown if ESR2 plays any regulatory role of hedgehog gene expression in GCs or ESR1 on the expression of hedgehog receptors.

We previously identified that the canonical transcription function of ESR2 is responsible for the regulation of PFA (4). In this study, we have explored the ESR2-regulated genes in developing rat ovaries to understand the mechanisms underlying ESR2 regulation of PFA. We identified that the expression $I h h$ and its downstream target Hhip is completely dependent on the presence of ESR2 in neonatal rat ovaries.

\section{Results}

\subsection{Alerted follicle activation in Esr $2^{\mathrm{KO}}$ rats}

We detected an increased activation of PdFs in $E s r 2^{K O}$ rat ovaries compared to age-matched wildtype. Increased number of PrFs were clearly evident on PND8 Esr $2^{K O}$ rat ovaries (Fig.1 E-I). While the cortical region in wildtype rat ovaries predominantly contained PdFs, it was replaced by PrFs in $E s r 2^{K O}$ rat ovaries. The total follicular counts of ovarian follicles in various stages of development remained similar between wildtype and $E s r 2^{K O}$ rat ovaries (Fig.1I).

\subsection{ESR2-regulated genes in neonatal rat ovaries}

To identify the transcriptional targets of ESR2, we performed RNA-sequencing of PND4, PND6 and PND8 $E s r 2^{K O}$ and age matched wildtype rat ovaries. Analyses of the RNA-seq data identified a large number of differentially expressed genes (DEGs) in $E s r 2^{K O}$. For further analyses we focused on the DEGs related to hedgehog, steroidogenesis, and folliculogenesis pathways (Fig. 2 A-C).

\subsection{Disruption of indian hedgehog signaling}

Among the transcripts with TPM values $\geq 1$, Ihh (Fig. 3A) showed the highest downregulation. Next to Ihh was the downregulation of IHH target gene Hhip (Fig. 3B). 
Downregulation of both Ihh and Hhip was consistent and increased from PND4 to PND8 ( $\mathrm{p}=0.00)($ Fig. 3A, B).
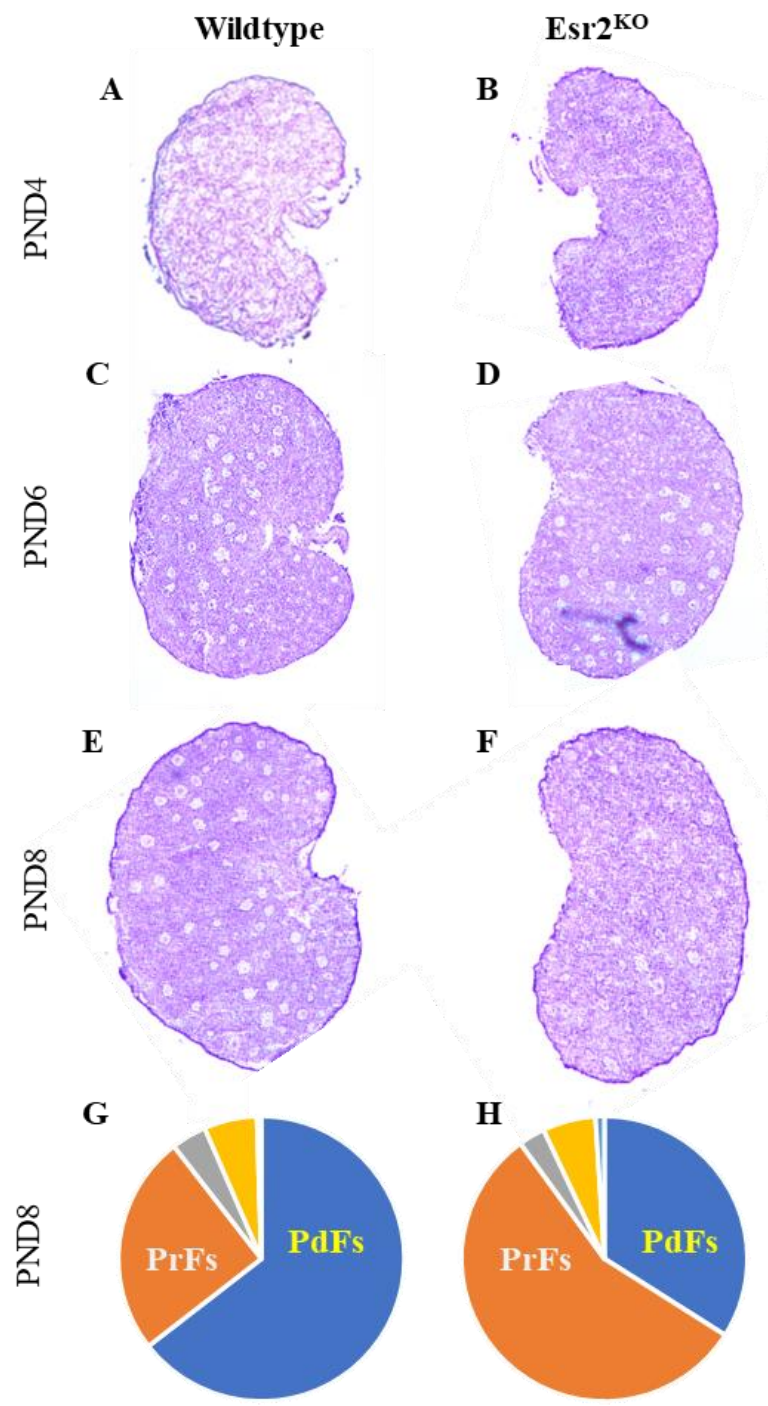

I

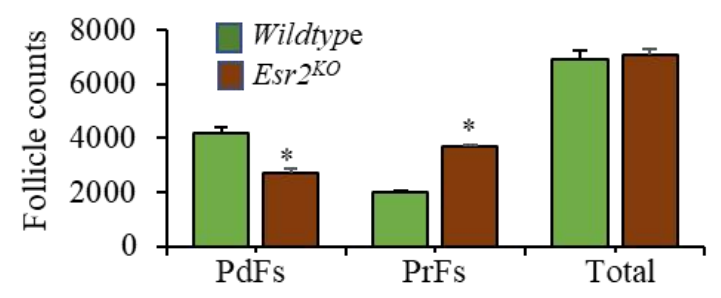

Figure 1. Increased PFA in $\boldsymbol{E s r} \mathbf{2}^{\boldsymbol{K O}}$ ovaries. Hematoxylin and eosin-stained sections of wildtype and Esr2 ${ }^{K O}$ PND4 (A, B), PND6 (C, D), and PND8 (E, F) rat ovaries showed increased activation of PdFs in $E s r 2^{K O}$ rats. Follicle counting in PND8 wildtype and $E s r 2^{K O}$ rat ovaries showed significantly decreased numbers of PdFs and increased numbers of PrFs (G-I). However, the total count of ovarian follicles in wildtype and $E s r 2^{K O}$ ovaries remained similar (I). Data shown as mean $\pm \mathrm{SE}, * p<0.05, \mathrm{n} \geq 3$.

Expression of hedgehog receptor Ptchl and hedgehog target Glil was also downregulated in $E s r 2^{K O}$ rat ovaries (Fig. 3C,
D). However, the expression of Gdf9 and Bmpl5 was significantly upregulated in $E s r 2^{K O}$ rat ovaries (Fig. 3E, F). The RNA-seq data were verified by RT-qPCR, which showed similar extent of Ihh, Hhip, Ptchl, Glil downregulation in PND8 Esr $2^{K O}$ rat ovaries (Fig. 4A-D). Upregulation of $G d f 9$ and Bmpl5 expression was also evident in PND8 Esr $2^{K O}$ rat ovaries (Fig. 4E, F).

A

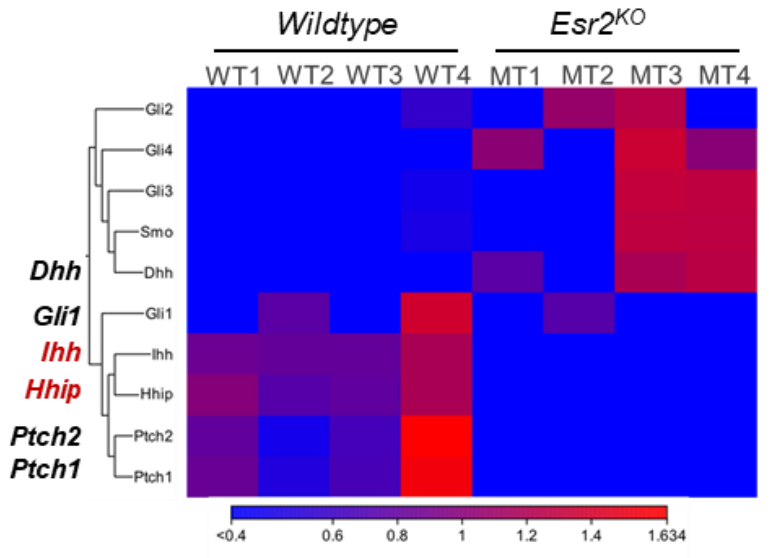

B

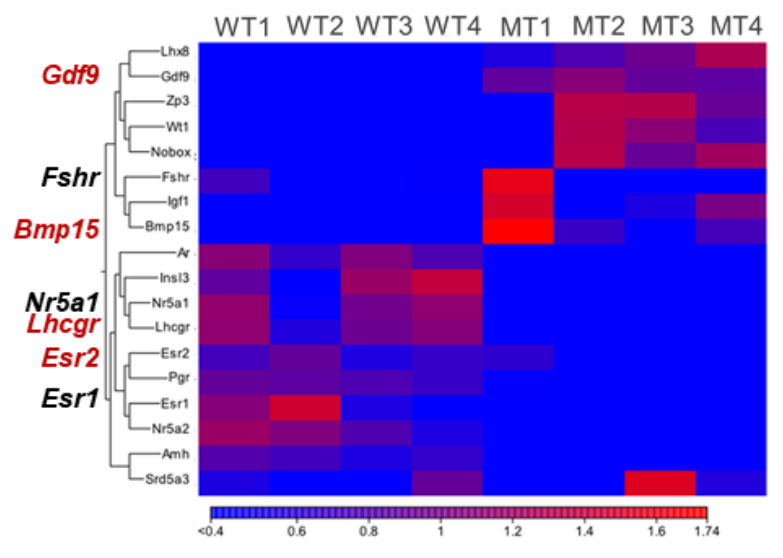

C

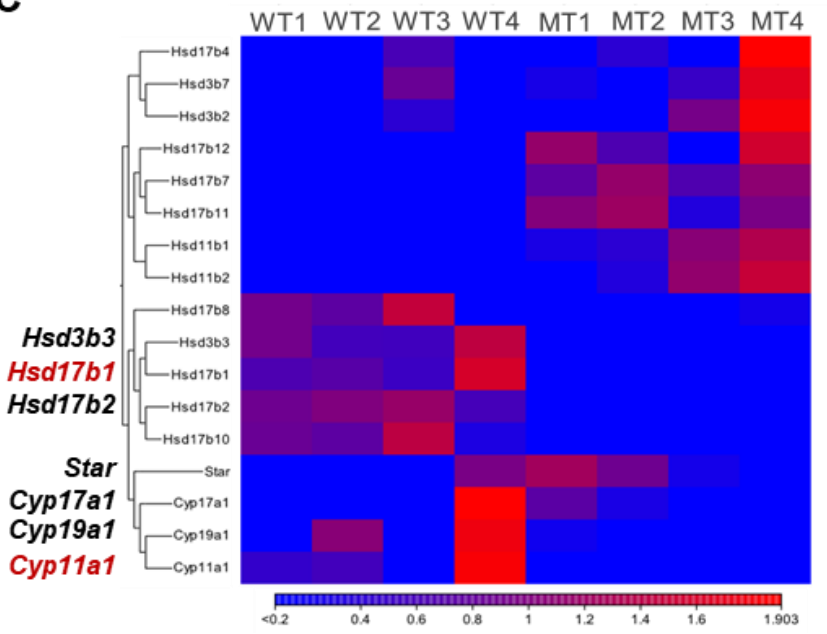

Figure 2. RNA-seq analysis of PND8 rat ovaries. RNA-seq analysis of PND8 rat ovaries showing differential expression of genes related to hedgehog pathway (A), steroidogenesis (B) and the key genes involved in folliculogenesis (C). 


\subsection{Altered expression of steroidogenic enzymes}

IHH signaling plays an important role in regulating the expression of steroidogenic enzymes. While analyzing the RNA-seq data, we identified that loss of ESR2 in Esr ${ }^{K O}$ rat ovaries disrupted the expression of Hsd17bl and Cypllal (Fig. 5A, C). Expression of gonadotropin receptor Lhcgr was significantly downregulated in $E s r 2^{K O}$ rat ovaries (Fig. 5F). However, the expression of $F s h r$ and FSH responsive gene Star remained unchanged in $E s r 2^{K O}$ rat ovaries (Fig. 5B, E).
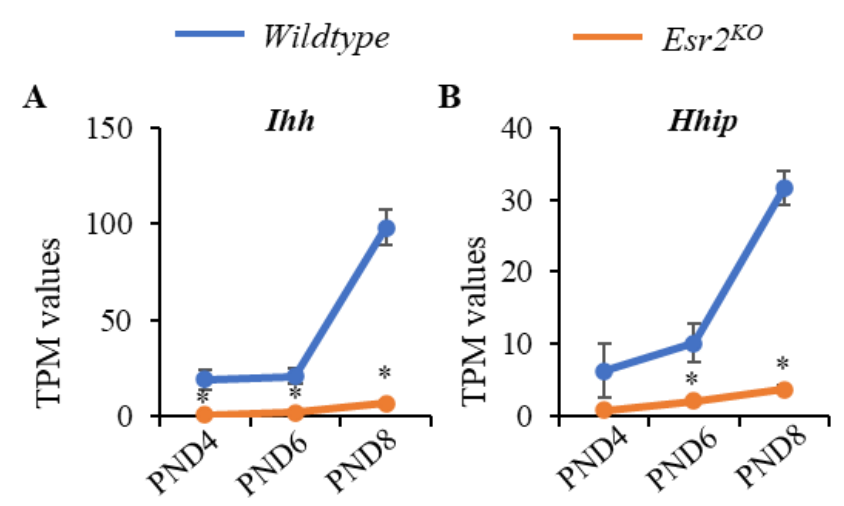

C

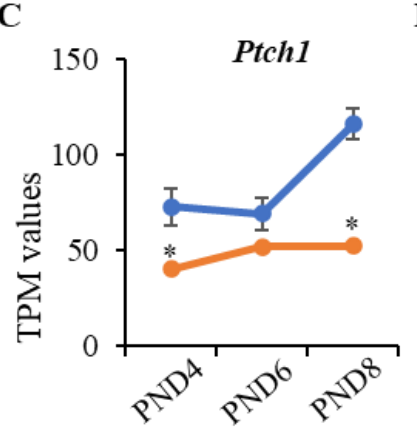

D
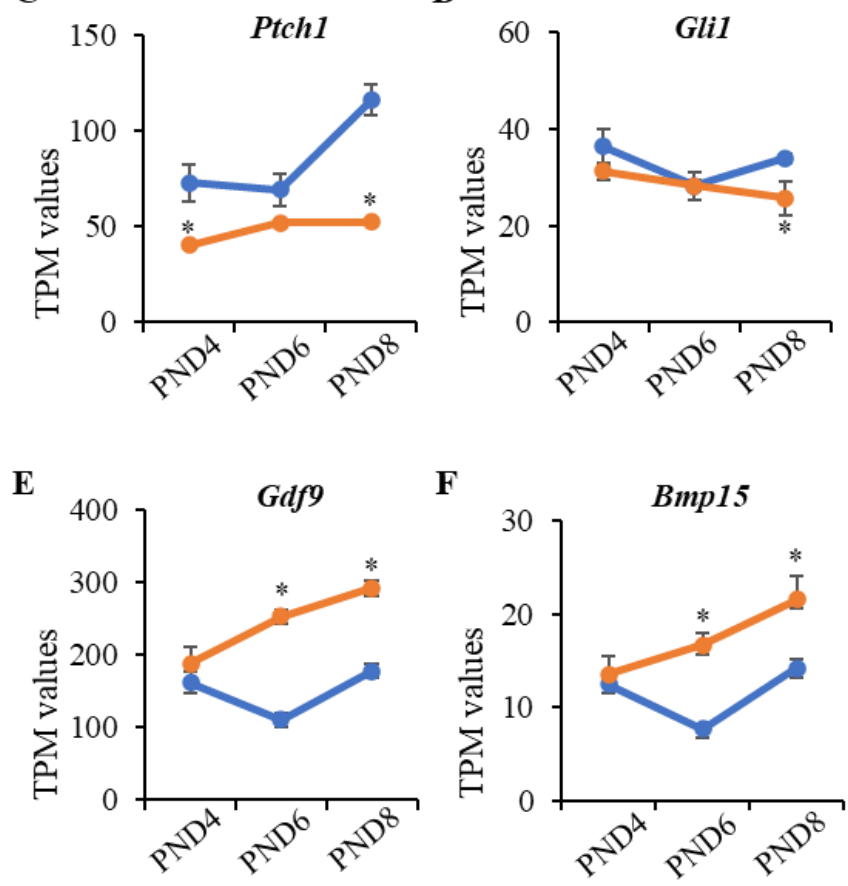

Figure 3. Loss of ESR2 disrupts indian hedgehog signaling. RNA sequencing analysis of PND4, PND6, and PND8 showed marked downregulation of $\mathrm{Ihh}$, its downstream targets Hhip and Glil, as well as its receptor Ptchl (A-D) in Esr $2^{K O}$ ovaries. However, its known regulators $G d f 9(\mathbf{E})$ and $B m p 15(\mathbf{F})$ were significantly upregulated in $E s r 2^{K O}$ ovaries. Data shown as mean \pm SE TPM values, $* p \leq 0.05, \mathrm{n}=4$.
The RNA-seq data were verified by RT-qPCR, which showed similar extent of Hsdl7bl and Cypllal downregulation in PND8 Esr2 $2^{K O}$ rat ovaries (Fig. 6A,C). Downregulation of Lhcgr expression was also evident in PND8 Esr2 ${ }^{K O}$ rat ovaries (Fig. 6F).
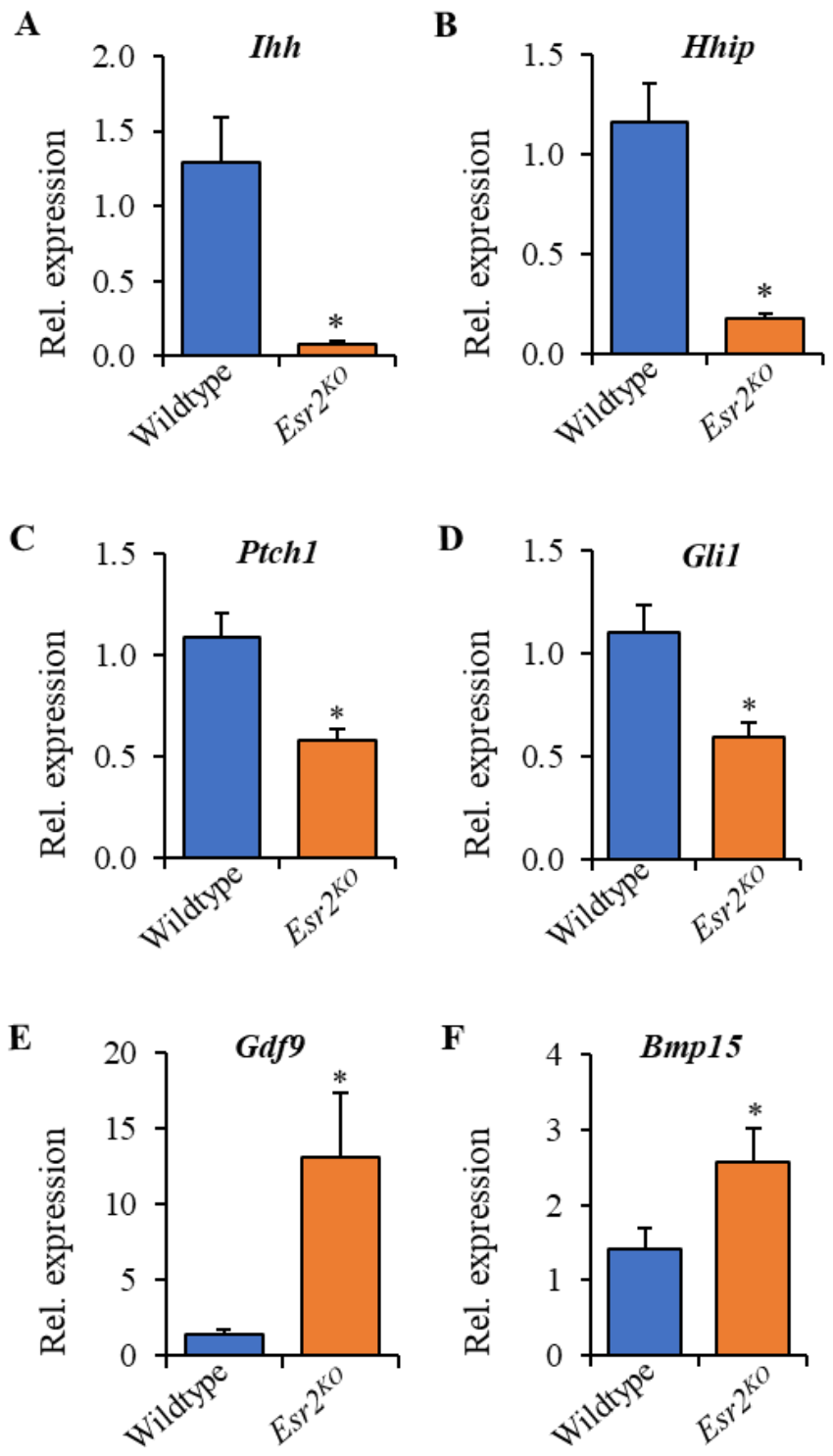

Figure 4. Verification of hedgehog signaling genes. RNA-seq data were verified by RT-qPCR on PND8 $E s r 2^{K O}$ rat ovaries. RTqPCR confirmed downregulation of Ihh, Hhip, Ptchl, and Glil (A-D), despite the marked upregulation of Gdf9 and Bmp15 (E, F). RT-qPCR data are shown as mean \pm SE. $* p<0.05, \mathrm{n}=6$.

\section{Discussion}

Findings of this study suggest an essential role of ESR2 signaling in the regulation of $I h h$ expression in neonatal rat ovary. GCs possess a high level of ESR2 expression (19, 20); thus, it is likely that Ihh expression in GCs is regulated by this ligand activated transcription factor. GCs in the 
activated ovarian follicles express the Ihh gene, which in turn act on premature TCs for induction of their development and differentiation $(12,21)$. Loss of $\mathrm{Ihh}$ expression in neonatal rat ovary was associated with a loss of Hhip expression in a similar fashion that was reported in $I h h^{K O}$ mouse ovary (13).

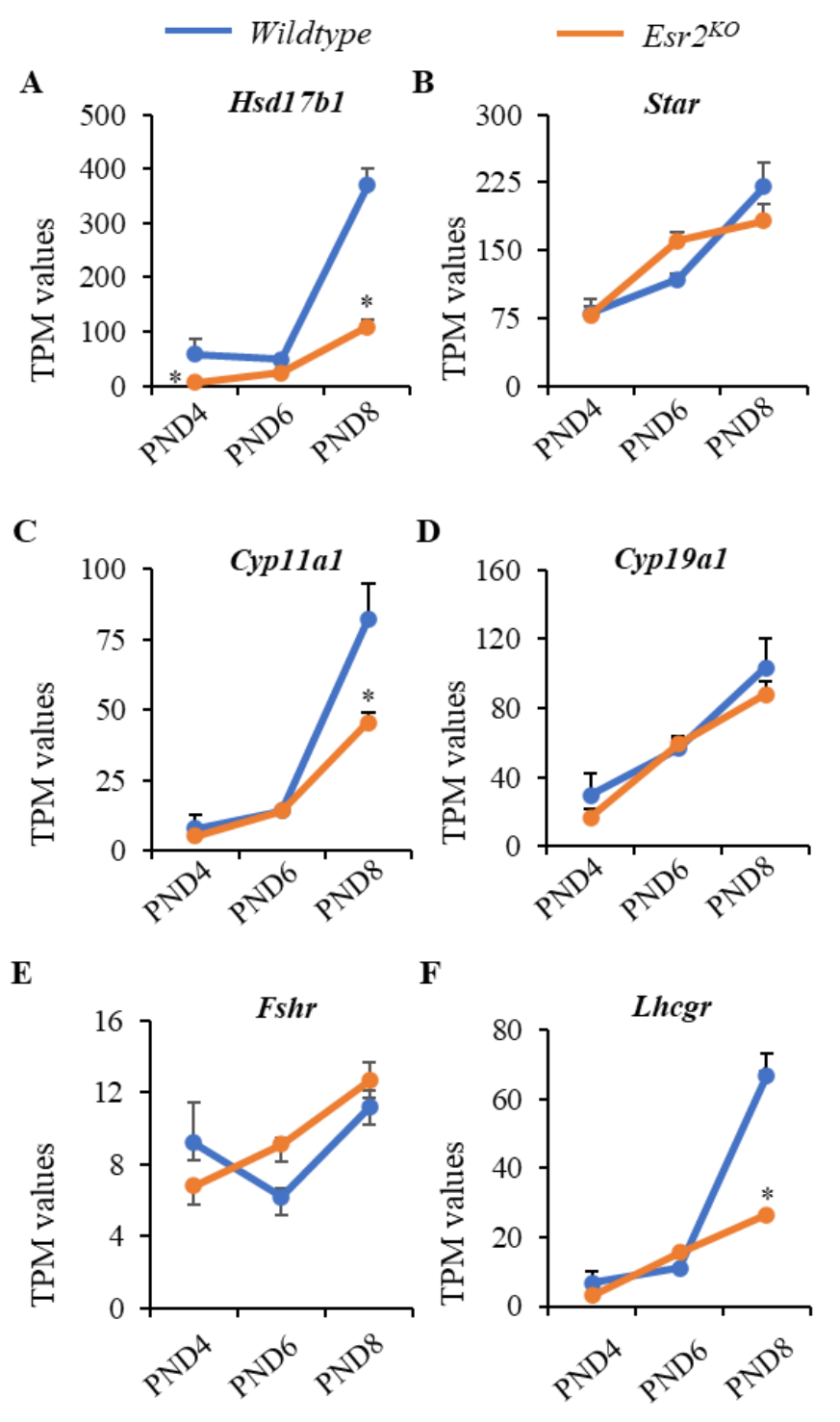

Figure 5. Loss of ESR2 disrupts expression of steroidogenic enzymes. RNA-seq analysis of PND4, PND6, and PND8 showed marked downregulation of Hsd17bl, and Cypllal (A, C) in $E s r 2^{K O}$ ovaries. However, the expression of Star, and Cyp19al did not show any significant changes in Esr $2^{K O}$ ovaries $(\mathbf{B}, \mathbf{D})$. While $F$ sh remained unchanged, expression of Lhcgr was downregulated in PND8 (E, F). Data shown as mean \pm SE TPM values, ${ }^{*} p \leq 0.05, \mathrm{n}=4$.

In addition to the development and differentiation of TCs, hedgehog signaling, particularly IHH, plays a pivotal role on regulation of ovarian steroidogenesis (14). In this study, we observed that lack of ESR2 dysregulated the expression of steroidogenic enzymes in $E s r 2^{K O}$ rat ovaries. Previous studies in $I h h^{K O}$ mice also reported a similar impact of lack of Ihh expression on ovarian steroidogenesis (13).
A

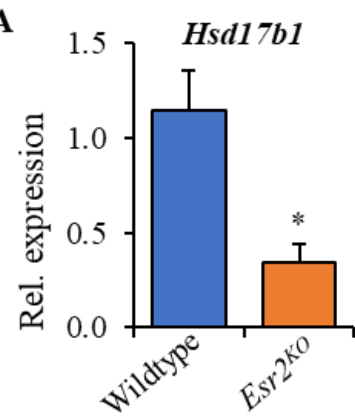

C

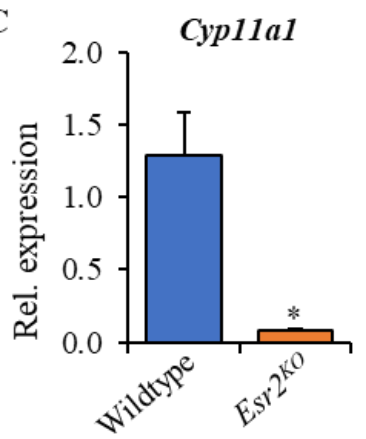

$\mathbf{E}$

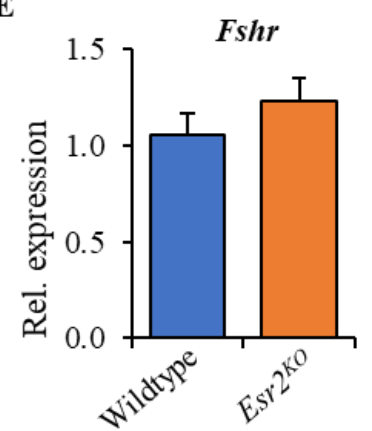

B

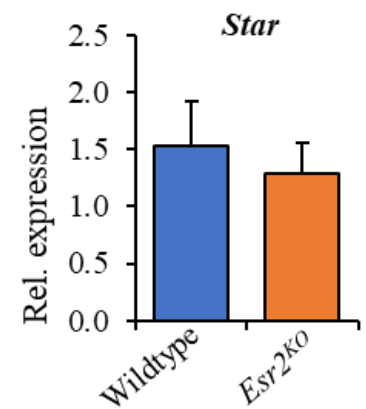

D

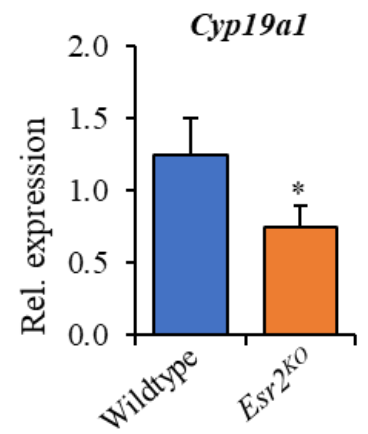

$\mathbf{F}$

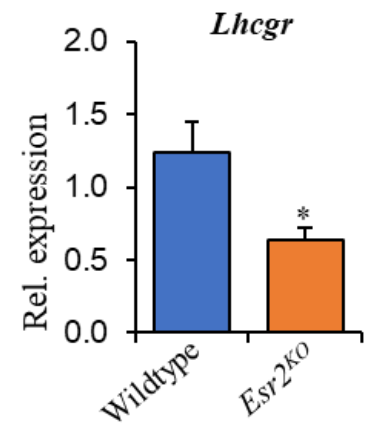

Figure 6. Verification of the expression of steroidogenic genes. RNA-seq data were verified by RT-qPCR on PND8 Esr $2^{K O}$ rat ovaries. RT-qPCR analyses confirmed the downregulation of steroidogenic enzymes Hsd17bl, Cypllal and Cyp19al. Downregulation of gonadotropin receptor Lhcgr was also similar to RNA-seq data. RT-qPCR data are shown as mean \pm SE. $* p<$ $0.05, \mathrm{n}=6$.

RNA-seq analyses identified altered expression of multiple steroidogenic enzymes, which can be either of GC or TC origin. It is well-known that loss of ESR2 affects the expression of GC-genes involved in steroidogeneses including Cypl lal and Cyp19al (1,2). We have observed that Ihh target gene Hhip, which is of TC origin, is dramatically downregulated in $E s r 2^{K O}$ rat ovaries. Thus, it is likely to observe downregulation of the steroidogenic 
enzyme genes in TCs, particularly those that are regulated by IHH signaling.

Previous studies have suggested that GDF9 and BMP15 expressed by the oocytes in activated follicles induce the expression of $I h h$ in mouse GCs $(12,22)$. In this study, we observed a very low level of Ihh and Hhip gene expression in neonatal $E s r 2^{K O}$ rat ovaries despite high levels of $G d f 9$ or Bmp15 expression. These observations indicate that GDF9 or BMP15 requires the presence of transcriptional regulator ESR2 to induce Ihh expression in GCs.

Although mice harboring ovary-specific $I h h^{K O}$ did not exhibit any ovulatory dysfunction (13), it does not exclude a possible role of IHH signaling in the regulation of PFA. Moreover, the representative images of $I h h^{K O}$ mouse ovaries appeared smaller than that of wildtype mouse ovaries (13), which is comparable to the relatively smaller sizes of $E s r 2^{K O}$ mouse or $E s r 2^{K O}$ rat ovaries $(1,23)$. We hypothesize that ESR2-regulated expression of $I h h$ from the activated follicles may act on dormant PdFs to control excessive PFA, which is observed in $E s r 2^{K O}$ rat ovaries (4). However, further studies are required to prove a mechanistic role of IHH in the regulation of PFA.

\section{Materials and methods}

\subsection{Animal models}

$E s r 2^{K O}$ mutant rats were included in this study. Esr $2^{K O}$ rats were generated by targeted deletion of exon 3 in Esr2 gene (1). Experimental animals were generated by breeding heterozygous mutant male and female rats carrying the $E s r 2^{K O}$ alleles. Rats were screened for the presence of mutations by PCR using tail-tip DNA samples (RED extract-N-Amp Tissue PCR Kit, Millipore-Sigma) as described previously $(1,24)$. Ovaries were collected from 4-to-8-day old $E s r 2^{K O}$ and age-matched wildtype rats for histological, and molecular studies. All animal experiments were performed in accordance with the protocols approved by the University of Kansas Medical Center Animal Care and Use Committee.

\subsection{Histological evaluation of ovarian phenotypes}

Ovaries were collected from 4-to-8-day old $E s r 2^{K O}$ and agematched wildtype rats. One ovary from each rat was embedded in OCT, frozen immediately and preserved at $80^{\circ} \mathrm{C}$ freezer till sectioning. The other ovary was snapfrozen in liquid nitrogen and preserved at $-80^{\circ} \mathrm{C}$ freezer till processed for RNA extraction. Histological sections were prepared using a cryotome. The frozen sections were prepared from whole ovaries at $6 \mu \mathrm{m}$ thickness and placed on charged glass slides (Fisher Scientific). Ovary sections were stained with hematoxylin and eosin (H\&E) following standard procedure (25). H\&E-stained sections were thoroughly examined for follicle morphology and counted for follicles in each stage of development as we have described previously (4).

\subsection{Detection of differentially expressed genes}

Gene expression at the mRNA level was evaluated by RNA sequencing (RNA-seq), conventional RT-PCR, and RTqPCR analyses. Total RNA was extracted from the whole ovary with TRI Reagent (Millipore-Sigma) and those with RIN values $\geq 9$ were considered for library preparation. 500 ng of total RNA from each sample was used for the RNAseq library preparation using the TruSeq stranded mRNA kit (Illumina, San Diego, CA) following the manufacturer's instructions. The cDNA libraries were evaluated for quality at the KUMC Genomics Core and then sequenced on an Illumina HiSeq $\mathrm{X}$ sequencer at Novogene Corporation, Sacramento, CA. All RNA-seq data have been submitted to the Sequencing Read Archive (SRX6955095-6955104). RNA-seq data were analyzed using CLC Genomics Workbench

\subsection{Validation of the differentially expressed genes}

Total RNA was extracted from the PND 8 ovaries using TRI Reagents (Sigma-Aldrich). 1000 ng of total RNA from each sample was used for the preparation of cDNAs in $20 \mu 1$ volume using High-Capacity cDNA Reverse Transcription Kits (Applied Biosystems, Foster City, CA). RT-qPCR amplification of cDNAs was carried out in a $10 \mu \mathrm{l}$ reaction mixture containing Applied Biosystems Power SYBR Green PCR Master Mix (ThermoFisher Scientific). Amplification and fluorescence detection of RT-qPCR were carried out on Applied Biosystems QuantStudio Flex 7 Real Time PCR System (ThermoFisher Scientific). The $\Delta \Delta C T$ method was used for relative quantification of target cDNA abundance representing mRNA expression level normalized to Rn18s (18S rRNA).

\subsection{Statistical analysis}

Each RNA-seq library was prepared using pooled RNA samples from 3 individual wildtype or Esr $2^{K O}$ rats. Each group of RNA-sequencing data consisted of four different libraries. For other experiments, each group consisted ovaries from a minimum of 6 rats, and all procedures were repeated for reproducibility. The data are presented as the mean \pm standard error (SE). The results were analyzed using one-way ANOVA, and the significance of mean differences was determined by Duncan's post hoc test, with $p \leq 0.05$. All the statistical calculations were done using SPSS 22 (IBM, Armonk, NY). 
Acknowledgments: This study was supported by funding from the KUMC SOM, COBRE, and K-INBRE.

\section{REFERENCES}

1. Rumi MAK, Singh P, Roby KF, Zhao X, Iqbal K, Ratri A, Lei T, Cui W, Borosha S, Dhakal P, Kubota K, Chakraborty D, Vivian JL, Wolfe MW, Soares MJ. Defining the Role of Estrogen Receptor beta in the Regulation of Female Fertility. Endocrinology. 2017;158(7):2330-43. Epub 2017/05/19. doi: 10.1210/en.2016-1916. PubMed PMID: 28520870; PMCID: PMC5505218.

2. Chakravarthi VP, Ratri A, Masumi S, Borosha S, Ghosh S, Christenson LK, Roby KF, Wolfe MW, Rumi MAK. Granulosa cell genes that regulate ovarian follicle development beyond the antral stage: The role of estrogen receptor $\beta$. Molecular and cellular endocrinology. 2021;528:111212. Epub 2021/03/08. doi: 10.1016/j.mce.2021.111212. PubMed PMID: 33676987.

3. Khristi V, Chakravarthi VP, Singh P, Ghosh S, Pramanik A, Ratri A, Borosha S, Roby KF, Wolfe MW, Rumi MAK. ESR2 regulates granulosa cell genes essential for follicle maturation and ovulation. Molecular and cellular endocrinology. 2018;474:21426. Epub 2018/03/28. doi: 10.1016/j.mce.2018.03.012. PubMed PMID: 29580824.

4. Chakravarthi VP, Ghosh S, Roby KF, Wolfe MW, Rumi MAK. A Gatekeeping Role of ESR2 to Maintain the Primordial Follicle Reserve. Endocrinology. 2020;161(4). Epub 2020/03/07. doi: 10.1210/endocr/bqaa037. PubMed PMID: 32141511.

5. Binder AK, Rodriguez KF, Hamilton KJ, Stockton PS, Reed CE, Korach KS. The absence of ER- $\beta$ results in altered gene expression in ovarian granulosa cells isolated from in vivo preovulatory follicles. Endocrinology. 2013;154(6):2174-87. Epub 2013/04/13. doi: 10.1210/en.2012-2256. PubMed PMID: 23580569; PMCID: PMC3740481.

6. Adhikari D, Liu K. Molecular mechanisms underlying the activation of mammalian primordial follicles. Endocrine reviews. 2009;30(5):438-64. Epub 2009/07/11. doi: 10.1210/er.2008-0048. PubMed PMID: 19589950.

7. Sun X, Su Y, He Y, Zhang J, Liu W, Zhang H, Hou Z, Liu J, Li J. New strategy for in vitro activation of primordial follicles with mTOR and PI3K stimulators.
Disclosure: The authors do not have any conflicts of interest.

Cell Cycle. 2015;14(5):721-31. Epub 2015/01/16. doi: 10.1080/15384101.2014.995496. PubMed PMID: 25590233; PMCID: PMC4615062.

8. Conti M, Hsieh M, Zamah AM, Oh JS. Novel signaling mechanisms in the ovary during oocyte maturation and

ovulation. Mol Cell Endocrinol. 2012;356(1-2):65-73. Epub 2011/11/22. doi: 10.1016/j.mce.2011.11.002. PubMed PMID: 22101318; PMCID: PMC4104635.

9. Zhang $\mathrm{H}$, Lin $\mathrm{F}$, Zhao J, Wang Z. Expression Regulation and Physiological Role of Transcription Factor FOXO3a During Ovarian Follicular Development. Front Physiol. 2020;11:595086. Epub 2020/12/01. doi: 10.3389/fphys.2020.595086. PubMed PMID: 33250784; PMCID: PMC7674958.

10. Russell MC, Cowan RG, Harman RM, Walker AL, Quirk SM. The hedgehog signaling pathway in the mouse ovary. Biology of reproduction. 2007;77(2):22636. Epub 2007/03/30. doi: 10.1095/biolreprod. 106.053629. PubMed PMID: 17392501.

11. Wijgerde M, Ooms M, Hoogerbrugge JW, Grootegoed JA. Hedgehog signaling in mouse ovary: Indian hedgehog and desert hedgehog from granulosa cells induce target gene expression in developing theca cells. Endocrinology. 2005;146(8):3558-66. Epub 2005/05/10. doi: 10.1210/en.2005-0311. PubMed PMID: 15878962.

12. Liu C, Peng J, Matzuk MM, Yao HH. Lineage specification of ovarian theca cells requires multicellular interactions via oocyte and granulosa cells. Nature communications. 2015;6:6934. Epub 2015/04/29. doi: 10.1038/ncomms7934. PubMed PMID: 25917826; PMCID: PMC4413950.

13. Liu C, Rodriguez KF, Brown PR, Yao HH. Reproductive, Physiological, and Molecular Outcomes in Female Mice Deficient in Dhh and Ihh. Endocrinology. 2018;159(7):2563-75. Epub 2018/05/23. doi: 10.1210/en.2018-00095. PubMed PMID: 29788357; PMCID: PMC6287595.

14. Finco I, LaPensee CR, Krill KT, Hammer GD. Hedgehog signaling and steroidogenesis. Annual review of physiology. 2015;77:105-29. Epub 2015/02/11. doi: 10.1146/annurev-physiol-061214- 
111754. PubMed PMID: 25668018; PMCID: PMC4820821.

15. Ren Y, Cowan RG, Harman RM, Quirk SM. Dominant activation of the hedgehog signaling pathway in the ovary alters theca development and prevents ovulation. Molecular endocrinology (Baltimore, $\mathrm{Md}$ ). 2009;23(5):711-23. Epub 2009/02/07. doi: 10.1210/ me.2008-0391. PubMed PMID: 19196835; PMCID: PMC2675960.

16. Spicer LJ, Sudo S, Aad PY, Wang LS, Chun SY, BenShlomo I, Klein C, Hsueh AJ. The hedgehog-patched signaling pathway and function in the mammalian ovary: a novel role for hedgehog proteins in stimulating proliferation and steroidogenesis of theca cells. Reproduction. 2009;138(2):329-39. Epub 2009/05/13. doi: 10.1530/rep-08-0317. PubMed PMID: 19433502.

17. Varjosalo M, Taipale J. Hedgehog: functions and mechanisms. Genes \& development. 2008;22 (18):2454-72. Epub 2008/09/17. doi: 10.1101/gad. 1693608. PubMed PMID: 18794343.

18. Franco HL, Yao HH. Sex and hedgehog: roles of genes in the hedgehog signaling pathway in mammalian sexual differentiation. Chromosome research: an international journal on the molecular, supramolecular and evolutionary aspects of chromosome biology. 2012;20(1):247-58. Epub 2011/11/23. doi: 10.1007/ s10577-011-9254-z. PubMed PMID: 22105695; PMCID: PMC3391966.

19. 19. Drummond AE, Fuller PJ. The importance of ERbeta signalling in the ovary. The Journal of endocrinology. 2010;205(1):15-23. Epub 2009/12/19. doi: 10.1677/joe-09-0379. PubMed PMID: 20019181.

20. Chakravarthi VP, Khristi V, Ghosh S, Yerrathota S, Dai E, Roby KF, Wolfe MW, Rumi MAK. ESR2 Is Essential for Gonadotropin-Induced Kiss1 Expression in Granulosa Cells. Endocrinology. 2018;159
(11):3860-73. Epub 2018/10/03. doi: 10.1210/en.201800608. PubMed PMID: 30277501; PMCID: PMC6260246.

21. Liu T, Qin QY, Qu JX, Wang HY, Yan J. Where are the theca cells from: the mechanism of theca cells derivation and differentiation. Chin Med J (Engl). 2020;133(14):1711-8. Epub 2020/06/13. doi: 10.1097/cm9.0000000000000850. PubMed PMID: 32530882 ; PMCID: PMC7401757.

22. Otsuka F, Yao Z, Lee T, Yamamoto S, Erickson GF, Shimasaki S. Bone morphogenetic protein-15. Identification of target cells and biological functions. The Journal of biological chemistry. 2000;275 (50):39523-8. Epub 2000/09/22. doi: 10.1074/jbc. M007428200. PubMed PMID: 10998422.

23. Dupont S, Krust A, Gansmuller A, Dierich A, Chambon P, Mark M. Effect of single and compound knockouts of estrogen receptors alpha (ERalpha) and beta (ERbeta) on mouse reproductive phenotypes. Development (Cambridge, England). 2000;127 (19):4277-91. Epub 2000/09/08. PubMed PMID: 10976058.

24. Rumi MA, Dhakal P, Kubota K, Chakraborty D, Lei T, Larson MA, Wolfe MW, Roby KF, Vivian JL, Soares MJ. Generation of Esr1-knockout rats using zinc finger nuclease-mediated genome editing. Endocrinology. 2014;155(5):1991-9. Epub 2014/02/11. doi: 10.1210/en.2013-2150. PubMed PMID: 24506075; PMCID: PMC3990838.

25. Picut CA, Swanson CL, Scully KL, Roseman VC, Parker RF, Remick AK. Ovarian follicle counts using proliferating cell nuclear antigen (PCNA) and semiautomated image analysis in rats. Toxicol Pathol. 2008;36(5):674-9. Epub 2008/05/10. doi: 10.1177/0192623308317428. PubMed PMID: 18467674. 